\title{
TOTALITARISMO DEMOCRÁTICO
}

Sergio Silva ${ }^{1}$

A questão sobre a redemocratização proposta como tema geral deste número de Idéias tem geralmente como referência o período que vai do fim dos governos militares aos nossos dias. É em relação a este período que geralmente estão reservadas as tentativas de avaliar a redemocratização de nossa maravilhosa Ilha de Santa Cruz. Como não acho que tenha havido nenhuma redemocratização no Brasil, minhas reflexões conduzem a uma caracterização diferente do período, como o próprio título deste texto indica. Donde, a meu ver, a revista definiu um tema cuja discussão é muito importante.

Se falarmos de redemocratização, estaremos admitindo que, anteriormente ao golpe militar de 1964, nossa Ilha viveu um período democrático. Esta é uma idéia muito questionável. Estou convencido de que não houve democracia nenhuma no Brasil, antes de 1964, e essa discussão só me interessa na medida em que abre caminho para uma tentativa de exposição sobre o que penso sobre o período posterior à ditadura militar. Por exemplo: o governo JK - por vezes apontado como um governo democrático - foi um dos governos mais antidemocráticos, talvez o mais antidemocrático da história brasileira. O governo JK foi o precursor da antidemocratização e do totalitarismo que vieram após a ditadura militar.

${ }^{1}$ Professor do Departamento de Sociologia do Instituto de Filosofia e Ciências Humanas da Universidade Estadual de Campinas. 
|122 |

Totalitarismo Democrático

Na verdade, não existe mais democracia em lugar nenhum. Pode ser que, algumas vezes, em alguns lugares, tenha havido democracia. Mas isso acabou há muito tempo, pois democracia é um regime político de governo e a política acabou. De um lado, a política acabou em razão da substituição de opções políticas por opções técnicas ou científicas, de modo que os candidatos a postos políticos não mais se diferenciam por opções políticas, mas simplesmente (por vezes, única e explicitamente) por suas capacidades de implementarem uma mesma "opção política". De outro lado, a política acabou com a substituição da igualdade de todos perante a lei (fim do Estado de Direito) pela imposição de um modelo geral de ser humano; modelo que todos devem seguir, para serem reconhecidos como dignos de viver.

Não falo aqui de nenhuma essência de democracia, mas de democracias, com muitos "s", ou de democracia em sua concepção corrente e simples, como regime de governo no qual as decisões (políticas) importantes são decididas, direta ou indiretamente (por representantes eleitos), pelas pessoas (cidadãs e cidadãos) que estão submetidas a este governo. E, ainda atrevidamente, considero o adjetivo "democrático" perfeito para caracterizar as formas de totalitarismo que passaram a dominar após a derrota de suas formas primitivas na primeira metade do malvado (e insolente) século XX. Após a segunda guerra mundial, o (pouco) que havia de democracia entrou em rápido processo de desaparecimento e o totalitarismo adotou as formas da democracia.

A opção pelo estudo do totalitarismo no lugar da inexistente democratização se justifica não somente pela evolução geral do planeta, mas, também e especificamente, pela evolução da sociedade brasileira, pois o Brasil pós-ditadura militar é justamente um dos lugares onde mais claramente se desenvolve o totalitarismo "democrático".

De todo modo, antes de explicar a expressão (dolorosa) "totalitarismo democrático", cabe explicar como é aqui usada a noção (muitas vezes, controversa) de totalitarismo. Para começar, 
com este palavrão tento nomear um sistema social (não um sistema político). O termo totalitário está associado ao controle sobre toda a vida da população. Na verdade, totalitarismo é simplesmente isso: um sistema social caracterizado pelo controle de toda a vida da população. Uma definição simples e fácil de entender, desde que não seja confundida com um controle total sobre a vida da população. O que define o totalitarismo não é o controle total da vida, mas o controle sobre todos os aspectos da vida.

A grande mudança em relação aos sistemas não totalitários está justamente no fato de que o controle social (do poder constituído, do

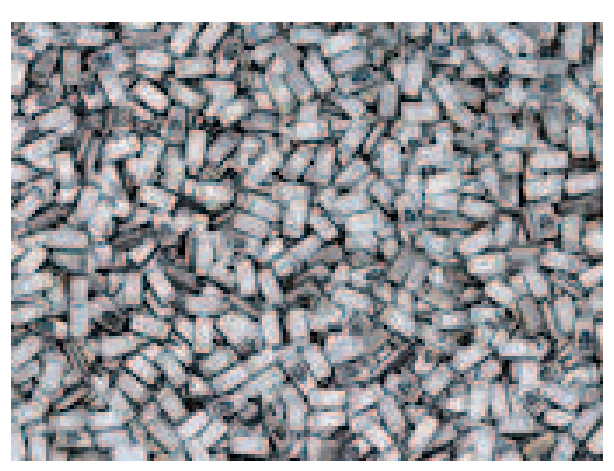

Estado) não se refere mais, fundamentalmente, à vida política da população (sobre a vida do cidadão; figura social que também desaparece). Refere-se a todos os aspectos da vida: a forma física e a saúde em geral, a instrução e a educação em geral, o lazer, o sexo, as fofocas e tudo-mais-nãofaz-falta-não! Afinal, um pouco do ritmo brasileiro é bom para lembrar que é do Brasil que se trata aqui e que o Brasil é destaque internacional do totalitarismo democrático, graças notadamente à crueldade de sua Mídia. A Mídia brasileira tenta (com sucesso invejável) afogar a maioria da população num tsunami de folhetins débeis mentais e muita informação; informação, a maior maldade da modernidade, como disse Benjamin. Quem tiver coragem, pode ouvir a CBN, a rádio que toca ideologia.

Por isso, acho necessário insistir e (espero) desenvolver a idéia de que controle social - em geral e no totalitarismo em particular - não significa, de forma alguma, controle total, no sentido do fim da resistência ao controle (ou dominação) social. No totalitarismo, em todos os aspectos da vida, encontramos resistência 
ao totalitarismo. Foucault assim como Deleuze e Guattari, ao tratarem esse tema ou temas correlatos, insistem na falta de sentido de falar em controle (ou qualquer forma de dominação social) e, ao mesmo tempo, supor o desaparecimento da resistência, a eliminação da resistência à dominação, ao controle. Sem resistência porque haveria controle? Para que serviria o controle? Na verdade, teoricamente, a resistência ao controle ou à dominação social é o fato primeiro. O controle é a reação contra a resistência. O controle e a dominação em geral são a reação à resistência.

A palavra resistência pode fazer pensar numa reação a algo que já existe. Se esse algo que já existe é a sociedade e o controle, uma distração semântica

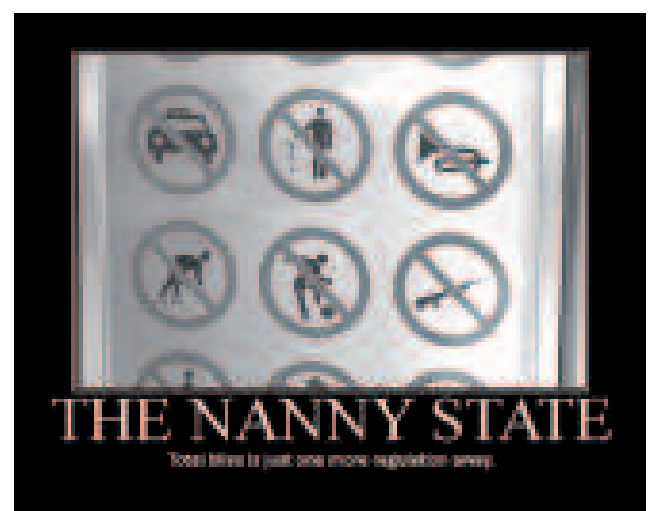
pode nos fazer pensar que a sociedade e o controle são o fato primeiro. Os defensores da sociedade, do controle e do totalitarismo amam de paixão esta distração pelo simples fato de verem nesta distração um modo de afirmar a mentira que defendem, com base no senso comum (no pior sentido da expressão) que nos faz pensar a sociedade como algo capaz de já existir antes das ações e relações sociais. Os fanáticos da ordem social estão convictos de que ações e relações sociais nada mais são do que resultados ou "emanações da estrutura social", de um "todo sempre já dado"!

Tais idéias constituem não somente um delírio idealista, mesmo que sob uma máscara materialista. Trata-se de um delírio muito conveniente ao poder constituído. Não é por outra razão que elas são amadas de paixão pelos ideólogos (de todas as cores) do poder constituído. A "estrutura social" mover-se-ia como 
uma entidade mística, divina. Por mais contraditório que isso possa parecer, esta entidade mística é, ao mesmo tempo, apresentada, vista, vendida e amada como entidade inteiramente racionalizada e naturalizada. Essa união entre divino, místico, natural e racional vem desde os albores da modernidade, mas é no século $X X$, no pequeno e malvado século $X X$, que ela encontra seu desenvolvimento pleno, sob o manto do totalitarismo.

Desde a Revolução Francesa, em especial com a Declaração de Direitos do Homem e do Cidadão, foi anunciado o desejo moderno de poder e foi anunciada a concepção do Estado moderno como instrumento do controle da vida, de toda a vida de todos os seres humanos. Os jacobinos escreveram belas páginas sobre esse maligno designo. $\mathrm{O}$ Terror pode ser visto como uma estréia (mesmo que parcial, modesta e cheia de erros) do totalitarismo que viria no Século XX; e que viria justamente com a retomada da idéia de uma passagem do poder político para o poder sobre a vida. O totalitarismo não está vinculado simplesmente ao poder de morte, o poder de acabar com a vida, coisa antiga. O poder totalitário é um poder sobre a vida vivida, sobre a vida mesmo. Por isso, é fundamental o destaque dado por Agamben ao primeiro Estado cuja constituição define a população como objeto central de seu poder. Esse Estado é o Estado nazista: a principal riqueza da nação é a sua população e o principal objetivo do Estado é defender a riqueza da nação. Inspirado em Foucault e Agamben, considero que, dessa forma, a política cede lugar à biopolítica.

Esta é uma das características centrais do totalitarismo: acabar com a política. Não quero, desse modo, reforçar as simpatias pelo totalitarismo em razão de sua tendência ao extermínio de algo que tanto mal fez e cujo fantasma ainda tanto mal faz aos seres humanos (e, através deles, a todos os outros seres deste planeta, inclusive os minerais). Apenas explicito essa verdade: o totalitarismo acaba com a política. Esta verdade é importante porque - insisto - a política, apesar de todos seus males, é contexto necessário à democracia. Não é possível imaginar democracia sem política. Isso não significa que, 
| 126 |

Totalitarismo Democrático

inversamente, não seja possível pensar ou mesmo ver, historicamente, política sem democracia. A ausência da democracia está no centro mesmo da ditadura, seja ela ditadura civil ou militar, caso do Brasil durante os vinte e um anos iniciados em 1964. Em todos os casos, a ditadura é pensada não somente como ausência de democracia, mas também - e fundamentalmente - como exceção ao Estado de Direito, isto é, exceção à forma geral que caracterizaria o Estado moderno. Esta característica é de tal forma geral e forte que ditadura e Estado de exceção seriam praticamente sinônimos.

O fim da política é próprio do Estado de Exceção Permanente que acompanha o totalitarismo. O fim da política e o fato de que, para a Exceção Permanente, não existem as antigas escolhas políticas, mas apenas o certo e o errado, apareceu de modo muito destacado com Fernando Henrique, que apenas juntou os gestos dos locutores globais ao seu velho discurso de professor. Lula, mesmo se de forma geralmente ridícula, manteve o tom. Outra característica do Estado de Exceção Permanente e do totalitarismo é a judicialização da política, cada vez mais difundida por todo o planeta. Por meio dela, o cadáver da política é despedaçado em praça pública. E isso é apresentado (todo dia, no Brasil) como política. Como judicialização da política é também politização da Justiça, assim vão todos os Poderes republicanos nos braços do totalitarismo.

Importante destacar - ou repetir de forma mais explícita que o simples Estado de Exceção (a ditadura) não elimina inteiramente a política. Em conseqüência, tanto a política como a democracia garantem suas existências sob a forma de ausências definidoras da ditadura e do Estado de Exceção. Ausências definidoras por serem elas que definem o sistema político vigente. $O$ Estado de Exceção define-se pela ausência (excepcional) do Estado de Direito. Isso vale também para a democracia, mas o Estado de Direito não implica necessariamente democracia. Muitos (entre os quais me incluo) não aceitam classificar qualquer sistema político que respeita o Estado de Direito como uma democracia. Sistemas políticos liberais podem respeitar o Estado 
de Direito e, ao mesmo tempo, definirem tantas e tão fortes restrições à participação na vida política que dificilmente podem ser considerados como sistemas políticos democráticos. Aliás, para muitos pensadores políticos liberais de renome, fortes restrições à democracia são essenciais para a existência mesma do Estado de Direito.

O desaparecimento da democracia resulta do mesmo processo que tem em seu núcleo a mudança do objeto do poder constituído, que passa do controle da vida política para o controle da vida em geral, de todos os aspectos da vida. Esta mudança é responsável pelo desaparecimento tanto da democracia, quanto da política (condição da democracia) e do Estado de Direito. Com o desaparecimento do Estado de Direito, constitui-se o Estado de Exceção Permanente, termo que tem a vantagem e a desvantagem de conter o termo "exceção", embora não seja uma exceção do Estado de Direito, mas algo qualitativamente diferente do Estado de Direito. É impossível ter um Estado de Direito se o objeto central do poder é a vida da população. A "mudança do paradigma jurídico" do Estado implica o fim do Estado de Direito...

Em conseqüência desta diferença qualitativa em relação ao Estado de Direito, não se deve pensar o Estado de Exceção Permanente como um simples Estado de Exceção, que se configura ainda nos quadros do Estado de Direito, como uma exceção dentro do Estado de Direito. Essa visão pode levar à tentativa de caracterizar o Estado de Exceção Permanente a partir de um acúmulo de medidas próprias ao Estado de Exceção. É preciso não confundir o Estado de Exceção Permanente com uma forma maior e mais generalizada do simples Estado de Exceção. O Estado de Exceção Permanente não é um Estado de Exceção mais completo ou mais fornido em termos de medidas de exceção. O Estado de Exceção Permanente não recusa apenas em caráter excepcional o Estado de Direito. O Estado de Exceção Permanente substitui o Estado de Direito. O Estado de Exceção Permanente põe fim ao Estado de Direito. A referência do Estado de Exceção Permanente não é o Estado de Exceção (do qual ele difere qualitativamente). $O$ Estado de Exceção Permanente tem como referência a sociedade totalitária. 
|128 |

Totalitarismo Democrático

No Brasil da "redemocratização", o desenvolvimento do totalitarismo e, em particular, do Estado de Exceção Permanente são exemplares. A nossa cordialidade imprime sua marca sobre ambos e, em particular sobre o Estado de Exceção Permanente. Em nossa Ilha, jamais vigorou o domínio da lei, no sentido dado a esta expressão por Edward Thompson. Em nossa Ilha, o domínio da lei foi subordinado ao império da cordialidade; cordialidade por vezes traduzida como "o jeitinho brasileiro", para esconder o sentido principal indicado pelo criador do homem cordial, Sergio Buarque, para quem a cordialidade é uma forma de dominação social. Graças a esta forma, no Brasil, o totalitarismo se desenvolve sem ter que enfrentar o problema do respeito à lei. No Brasil, a lei é "para os amigos tudo, para os inimigos a lei", "a lei foi feita para ser interpretada" etc.

Isso não significa uma necessária precedência da sociedade totalitária em relação ao Estado de Exceção Permanente. A relação que estabeleço é uma relação abstrata. Concretamente, o Estado de Exceção Permanente é um elemento central na construção da sociedade totalitária. Este me parece ser o caso das primeiras formas de totalitarismo; formas fundamentais para o totalitarismo de hoje. Penso no fascismo, no nazismo e no comunismo stalinista. Entretanto, a derrota destas formas de totalitarismo não corresponde à derrota - ou mesmo a uma derrota - do totalitarismo em geral (com as devidas desculpas à Hanna Arendt, que admiro sinceramente; e os devidos parabéns a Hans-Jürgen Syberberg, em especial por seu "Hitler, um filme da Alemanha").

O que afirmei no parágrafo anterior torna importante indicar a existência de elementos fundamentais do totalitarismo nas sociedades ainda não totalitárias. Os principais dirigentes e os grandes ideólogos das primeiras formas de totalitarismo não eram gênios completos, apoiavam-se em idéias cujos desdobramentos - vistos de nossos dias - parecem conduzir diretamente ao totalitarismo. Um exemplo? O anti-semitismo era larga e fortemente difundido na Europa, bem antes de Hitler justificar uma "solução final", apoiado - aliás - no exemplo da ação dos "norte-americanos" em relação aos índios (ouso dar 
esse exemplo, embora seja chocante a ignorância de Hitler sobre o caso brasileiro). As idéias totalitárias floresceram desde o início da modernidade, mas só no pequeno, malvado e insolente século $\mathrm{XX}$ surgem as sociedades totalitárias.

Por favor, não busquem aqui uma análise determinista sobre o totalitarismo: o que afirmo se apóia na negação do determinismo. Weber afirma enfaticamente esta negação, em parte através de crítica a Marx. Pobre Mouro. A negação do determinismo foi ensaiada por ele também; e - apesar dos marxistas - é o único caminho para levar adiante a sua idéia sobre a sociedade como um conjunto de relações sociais reais, isto é, ações de seres humanos (pensantes, como lembra Caio Prado). As (poucas) referências que faço às idéias totalitárias anteriores às sociedades totalitárias e ao Estado de Exceção Permanente não indicam relações de causa e efeito, mas afinidades eletivas, essas "escolhas das causas pelos efeitos" que parecem tão difíceis de entender.

Com afinidades eletivas muito especiais, variadas e complexas, o "americanismo" parece ter sido uma verdadeira surpresa para Adorno \& Horkheimer. Eles imediatamente identificaram não só um totalitarismo, como na Alemanha, mas um totalitarismo do tipo que chamo aqui de "totalitarismo democrático", um totalitarismo que talvez possa ser resumido no American Way of Life. Desse ponto de vista, o estudo sobre a indústria cultural é o texto mais importante da importantíssima coletânea sobre o Esclarecimento que os dois nos deixaram. Dito isso, não resisto em lembrar a importância da contribuição do Estado para o americanismo: é preciso considerar devidamente a contemporaneidade entre o New Deal, os planos qüinqüenais soviéticos e a economia alemã sob o nazismo.

Com boa vontade, podemos encontrar surpresa semelhante em escritos de Weber, algumas décadas antes dos textos de Adorno \& Horkheimer. No caso de Weber, uma surpresa envolvida pela admiração de quem vê, diante de seus olhos, a sociedade que mais se aproximaria do que ele chamava de modo de dominação burocrático: a sociedade norte-americana. A 
|130 |

Totalitarismo Democrático

surpresa e a crítica ocupam muitas entrelinhas, no mais puro estilo Clarice Lispector; o que não me parece nada surpreendente em Weber. Ademais, podemos lembrar que para Weber - já em 1917, logo após a tomada do poder pelos bolcheviques - a URSS deveria ser analisada como dominação burocrática em nível quase absoluto.

Gostaria de aproveitar este assunto para lembrar que a idéia weberiana de burocracia nada tem a ver com o que correntemente se

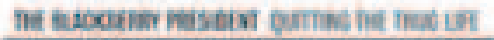
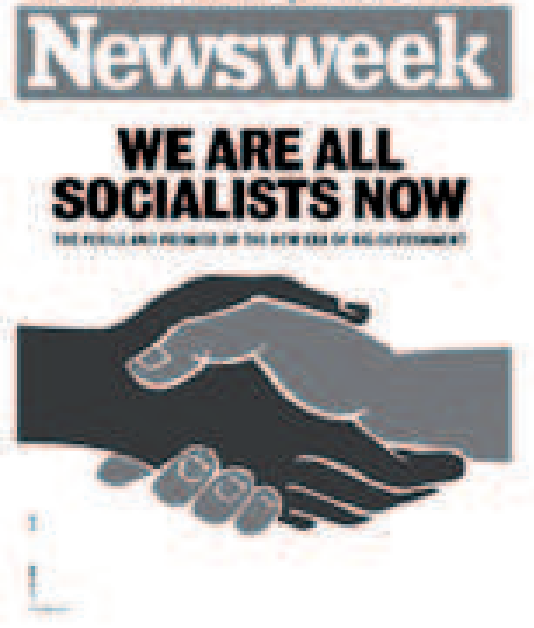
reconhece como burocracia (a burocracia pública ou mesmo parte dela). Nada a ver. Para Weber, a dominação burocrática tem seu fundamento na empresa privada, no capitalismo e em sua divisão racional do trabalho. Posso até imaginar a felicidade de Weber ao contrapor-se de modo tão frontal a Hegel: o Estado moderno seria o Estado fundado na burocracia da empresa privada. Para Weber, ao tentar tirar a medalha de ouro da economia política inglesa, Hegel seria ridículo. Infelizmente, muitos preferem seguir o sentido corrente - tão pobre! tão enganador! - do termo burocracia.

O parágrafo anterior não representa um desvio de nosso tema. Hoje, é evidente que o totalitarismo, além de levar adiante (quase ao absoluto) o modo de dominação burocrático, estabelece uma nova associação - nem sempre realizada, mas sempre presente e necessária - entre dominação burocrática e carisma. Talvez Weber ficasse horrorizado com isso. Talvez tenha tido pesadelos ou sonhado com isso. Talvez ficasse encantado com o 
nazismo, como outros acadêmicos. A vida é dura, mas, de lá para cá, o totalitarismo avançou muito, fez muitos progressos. O louvor à ciência, à tecnologia e à burocracia que delas se encarrega é feito sem reservas, independentemente do mal que elas fazem a todos os seres que habitam este planeta (inclusive os humanos); apenas ajustes são reclamados aqui e ali, para que o planeta não exploda rapidamente. Diante do atual massacre midiático em torno deste louvor, a lavagem cerebral dos antigos regimes totalitários parece brincadeira de criança. Como nos ensina Estamira, os cientistas são os novos deuses. Realmente, eles têm um lugar privilegiado no Olimpo moderno, quase no mesmo nível de Angelina Jolie ou Xuxa (a ideóloga do capitalismo vídeo-financeiro).

Mas não basta ser adepto incondicional da ciência, da bomba atômica aos celulares, é preciso também ter charme; um charme especial, que aproxime o "olimpiano" do homem comum. É preciso unir servidão à ciência e carisma. Os grandes modelos para as novas estrelas que passaram a brilhar no antigo céu da política foram também os fundadores do totalitarismo: talvez Stalin, certamente Mussolini e, sobretudo, Adolf Hitler, o mestre em simpatia, em aclamação das massas, em beijar crianças, liderar reuniões mais ou menos apoteóticas. Hoje, o esforço deve ser ainda maior para chegar perto de Ana Maria Braga ou George Clooney. O congresso nazista de 1934, em Nuremberg, foi o primeiro grande show do totalitarismo e foi devida e magistralmente montado e filmado por Leni Riefenstahl. Os Estados Unidos e a União Soviética já davam lições neste terreno. Mas o show e o filme nazistas são exemplares; tornaram-se referências para toda a vida social e são agora multiplicados pelos vídeos, DVDs, TVs, computadores, com seus espetáculos de educação e informação, lazer ou esporte e tudo o que pode servir para o controle e a apologia do controle da vida. E, neste terreno, o Brasil se notabiliza, sobretudo após o fim dos governos militares, isto é, com a chamada redemocratização.

A repressão tradicional, em especial a tortura, em lugar de desaparecer, generalizou-se. A Mídia, entretanto, 
representa o meio mais notável de controle e repressão nas sociedades modernas, em especial no totalitarismo. Afinal, a Mídia é a principal responsável por tornar concreta (e aparentemente insuperável) a idéia de que você só pode viver se for devidamente informado sobre a sua vida (as indicações de Benjamin sobre a maldade da informação estão entre as maiores preciosidades de todos os tempos). Ora, o Brasil é não somente campeão mundial de tortura, como

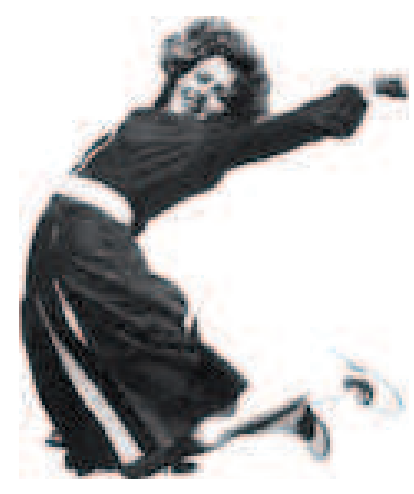
campeão mundial de Mídia. A esses elementos fundamentais do totalitarismo democrático (tortura contra bandido e pobre faz parte da democracia totalitária), devemos juntar todo o espetáculo eleitoral organizados pelos famosos Três Poderes. Espetáculo que seria impossível sem a ajuda decisiva das associações de empresários (cada vez mais folgadas), das associações de trabalhadores (cada vez mais servis), das ONGs (cada vez mais caras de pau) e, sobretudo, da Mídia (com destaque para a forma moderna da tortura: a pesquisa de opinião pública). Um papel muito especial é reservado para a informática. Ele justifica a nota dez para o Brasil também no quesito eleições: as apurações são feitas por programas de computação sobre os quais não há nenhuma fiscalização. É realmente espetacular.

Sociedade do espetáculo é o nome que Guy Debord usa para analisar a sociedade totalitária de hoje; este nome tem a vantagem de destacar o seu aspecto fundamental: a transformação da vida em espetáculo. Na sociedade do espetáculo, os que hoje ocupam o lugar de líderes políticos (e assim são tratados, apesar do fim da política) só excepcionalmente apresentam alguma característica - mesmo que simples aparência - da época anterior ao nazismo. Apesar de muitos progressos terem sido feitos, Hitler - como modelo - ainda não foi superado, nem mesmo 
nos Estados Unidos, onde, após décadas de desenvolvimento da indústria em geral, da indústria cultural e da sociedade do espetáculo, o totalitarismo democrático é cada vez mais forte.

São inegáveis os esforços e os resultados da sociedade do espetáculo - isto é, do totalitarismo de hoje - nos Estados Unidos, inclusive no que se refere à formação das celebridades do poder constituído (no caso, do Estado de Exceção Permanente). Estes esforços vêm sendo feitos, sistematicamente e sem intervalos, desde Roosevelt, passando por Eisenhower e Kennedy, inclusive com apelos a estrelas cinematográficas, como Reagan, Frank Sinatra e Marilyn Monroe. O sucesso de Bill Clinton é inimitável. No Brasil, o moreno Fernando Henrique conseguiu notabilizar-se por ter "um pé na cozinha". Bill Clinton, brancão, conseguiu ser considerado como o primeiro presidente negro dos Estados Unidos, apesar do que a Mídia precisa dizer hoje para exaltar o esforçado Obama. Feliz ou infelizmente, a Europa avançou com maiores dificuldades nesse terreno. Quem acredita em Tocqueville, pode atribuir este fato às tradições aristocráticas européias. De todo modo, além da performance patética de Tory Blair (em tudo inferior à de sua antecessora Margaret Thatcher), é justo destacar os esforços atuais de celebridades tão diversas quanto Putin, Berlusconi, Sarkozy e Ioulia Timochenko.

Assim, uma análise comparativa permite destacar, com orgulho, a grande contribuição brasileira ao totalitarismo. Vargas e JK podem ser apontados como exemplos dos primeiros passos do nosso totalitarismo e de nossos líderes carismáticos, mas, após a ditadura militar, nosso progresso foi realmente sensacional. A contribuição é bem variada. Sarney e Itamar mantiveram poses de político tradicional. Entretanto, não é possível esquecer o Plano Cruzado e o Plano Real. O Cruzado é uma beleza. Sarney visava unicamente destruir os seus principais inimigos (Brizola e, sobretudo, Ulisses Guimarães). Em termos de política (que não mais existia), o Cruzado foi um golpe branco: um conjunto de medidas, que alteravam radicalmente as normas de funcionamento da sociedade brasileira, adotada de modo que nem Legislativo, nem Judiciário pudessem sobre elas opinar. 
| 134 |

Totalitarismo Democrático

Mas o Plano Cruzado não pode ser entendido unicamente a partir de Sarney e seus objetivos "políticos": suas implicações ultrapassam, de longe, o golpe de Estado branco. Como o Cruzado foi obra de burocratas brasileiros que haviam elaborado o Plano Austral, pouco antes aplicado na Argentina, é justo dividir as glórias do Cruzado com o Austral: os dois compõem um marco internacional do totalitarismo de hoje. O Austral, o Cruzado e os planos que os seguiram são também marcos do Estado de Exceção Permanente.

Nesse particular, talvez caiba outro destaque para o Brasil: a capacidade de alterar a lei sem alterá-la, evitando encher os textos legais de dispositivos identificados como "de exceção", A cordialidade adora usar a lei de forma perfeitamente ilegal. Por isso, os efeitos do Cruzado foram muito mais profundos. Uma das diferenças marcantes dos governos ditos democráticos em relação à ditadura militar reside justamente nessa capacidade de desrespeitar inteiramente dispositivos fundamentais da lei e mesmo das constituições federais e estaduais, sem que seja sequer cogitada a possibilidade de suprimir - ou mesmo alterar marginalmente - leis e constituições. Para citar um exemplo bem próximo das universidades estaduais paulistas, lembro a criação da Secretaria de Ensino Superior em total (e debochado) desrespeito à constituição estadual, no primeiro dia de um governo, sem que isso levasse ao impedimento do dito governador. Aqui, nunca houve mesmo um império da lei. Hoje, vivemos sob Estado de Exceção Permanente cordial.

Não é, então, por acaso, que o Brasil é reconhecido como potência internacional emergente de primeira linha. Tratase de um reconhecimento à contribuição brasileira para o totalitarismo democrático e politicamente correto; contribuição geral e contribuições como, por exemplo, a ocupação militar do Haiti. Para completar este reconhecimento consensual, o Brasil tem Lula. Por isso, em 2009, o jornal Le Monde criou o título de Homem do Ano e atribui-o a Lula. Ainda no mesmo ano, a imparcial revista The Economist, em matéria de capa, "Brazil Takes Off", mostrou-se simplesmente encantada com o governo Lula. 
Uma celebridade brasileira parece estar conseguindo aperfeiçoar o modelo de Adolf Hitler. Os líderes (em alemão: führers) são perigosos, mas o totalitarismo e o Estado de Exceção Permanente precisam de líderes.

Não houve nenhuma democratização no Brasil. Democracia não existe mais. Não existe mais política, nem Estado de Direito, mas a contribuição brasileira para o totalitarismo politicamente correto é inestimável. Não se trata somente de nosso simpático líder. Trata-se do que os donos do Brasil conseguiram em termos de organização social, quase sempre sob o título de "redemocratização". O poder incomensurável da Mídia, das prisões, das leis camaleoas (sem querer ofender as lindas camaleoas). Destaque especial: as constituições que não são constituições de verdade, porque seus fundamentos podem ser (e são) alterados a qualquer momento, com um pequeno pacote de PECs (não confundir com MP ou MPB, com PAC ou telecoteco). O controle sobre todos os aspectos da nossa vida talvez seja o maior do mundo.

Mas este controle, por maior que seja, enfrenta resistência e resistências variadas. Um novo banditismo destaca-se pelas suas semelhanças com a falecida política: talvez seja apenas a falecida política por outros meios. Mas não precisamos apoiar a repressão. Podemos abrir os olhos para as muitas e variadas resistências que se desenvolvem em todos os aspectos da vida, geralmente por pura e simples questão de sobrevivência, pois, afinal, o que está em jogo é a possibilidade de retomarmos o que Eles nos tomaram: a vida. Todos devemos ou precisamos resistir um pouco. E, para isso, nem precisamos deixar de reconhecer que o Brasil redemocratizado é fan-tás-ti-co!

\footnotetext{
* As fotos aqui presentes não são ilustrações de nenhuma parte do texto. Elas desenvolvem o tema geral definido no título).Todas as fotos foram encontradas em busca Google de "totalitarism copy free picture". 